\title{
Strength and transportability of cemented phosphogypsum paste backfilling slurry
}

\author{
Diyuan Li Central South University, China \\ Bing Liu Central South University, China \\ Jiang He Central South University, China \\ Xibing Li Central South University, China \\ Mingxing Jian Guizhou Kailin Mining Corporation, China
}

\begin{abstract}
In order to investigate the strength of cemented phosphogypsum (PG) backfill, a batch of PG backfilling slurry with different concentrations were tested at different curing times. Furthermore, a full-scale pipe test loop system was also established to investigate the pressure drop of the paste slurry with varied slurry concentrations and mix proportions flowing through the pipes. The test results showed that the compressive strength of the cemented PG backfill specimens was influenced by the ratio of the cementitious material to $P G$, the slurry concentration and the curing time. For example, under 28 days of curing time, the compressive strength of the cemented $P G$ backfill specimens with the slurry concentration of $68 w t \%$, mixed with the ratio of cementitious material to PG being 1:2, can reach 3.4 MPa. Based on the pipe test loop system, the fitting calculation formulas for the pressure drop of cemented PG paste backfill slurry (CPPB) with two ratios of cementitious materials to PG (1:4 and 1:5) flowing in horizontal straight pipes have been put forward. A field test was also conducted that proved the reliability of the fitting calculation formula.
\end{abstract}

\section{Introduction}

Phosphogypsum (PG), a by-product derived from the production of phosphoric acid by "wet acid method", is composed mainly of calcium sulfate dihydrate $\left(\mathrm{CaSO}_{4} \cdot 2 \mathrm{H}_{2} \mathrm{O}\right)$ and impurities such as phosphate, fluorides and so on (Carbonell et al., 2002; Zhou et al., 2012). Approximately $100 \sim 280$ million tons of PG are generated per year around the world (Parreira et al., 2003; Yang et al., 2009), while 85\% of which is usually dumped in large stockpiles without any treatment, occupying a great amount of available land and causing environmental damage (Tayibi et al., 2009). In order to improve the recycling rate of PG, attempts have been made to use PG as building materials, agricultural fertilizers, Portland cement retarder and etc. (Akın and Sert, 2004; Değirmenci, 2008; Mun et al., 2007). However, few researches have investigated the application of PG in mining activities. Li et al. (2008) have used PG, fly ash and Portland cement to investigate the feasibility of using PG to backfill the mine-out area. It was found that with the cement-fly ash-PG ratio of 1:1:6, a desired strength performance as well as fluent transportability into the underground mine-out areas can be achieved. However, the use of Portland cement is expensive and hence, the cost of cementitious materials should be reduced to promote the PG backfill technology.

Yellow phosphorus slag (YPS) is a solid waste generated from the industrial production of yellow phosphorus (Lebedeva et al., 2000), with approximately $8 \sim 10$ tons of YPS produced from 1 ton of yellow phosphorus. 
With the potential coagulation property of YPS (e.g. Chen et al., 2010), a composite material (CM), mixed by YPS, Portland cement, $\mathrm{CaO}$, fly ash and so one, is more cost-effective than Portland cement.

There are mainly three types of cemented backfill in mines, namely, cemented hydraulic, rock, and paste backfills (Amaratunga and Yaschyshyn, 1997; Fall et al., 2010). Recently, for the filling of underground mineout areas, cemented paste backfill (CPB) is increasingly used due to its great technical and economic advantages, such as improving working environment and ground control and increasing resource recovery (Kesimal et al., 2005; Yilmaz, 2010).

The application of PG and cementitious CM in underground filling operations by CPB technology would not only increase the recycle rate of both PG and YPS but also help to alleviate the environmental pollution caused by PG and YPS. The cemented PG paste backfill (CPPB) slurry is a mixture of PG, CM, and water in a certain proportion. Furthermore, as the cemented paste backfill placed in the underground mine-out areas should ensure a safe underground working environment, the cemented PG backfill must satisfy the demands of certain mechanical stability (Fall et al., 2004). Numerous efforts have been made to investigate the mechanical properties of cemented paste backfill slurry mixed with tailings and Portland cement (Fall et al., 2010; Jiang et al., 2016), but the mechanical properties of cemented PG backfill still remain unknown. In addition, the filling operation cannot well work if the transportation of backfill slurry underground mines fails. The delivery of backfill slurry from prepare station to underground mine-out stopes is usually through the gravity flow system or pumping system (Hewitt et al., 2009). Hence, it is crucial to investigate the transportability of backfill slurry. Wu et al. (2015a, b) used pipe test loop system to investigate the transportability and pressure drop of cemented coal gangue-fly ash backfill slurry with varied concentrations and mix proportions. However, as PG and YPS each has its own unique physical and chemical properties, the results obtained from previous research cannot be directly applied to CPPB slurry. For the purpose of developing CPPB technology, this paper conducts the uniaxial compressive test as well as loop pipe test to obtain the mechanical properties and transportability of cemented PG backfill slurry.

\section{Mechanical test of cemented PG backfill specimens}

\subsection{Materials}

The materials of the cemented PG backfill specimens are PG, CM and water. As shown in Table 1, the distribution of $P G$ particle size is relatively uniform, indicating the great tendency of $P G$ to be mixed in the preparation of backfill slurry. As listed in Table 2, the content of $\mathrm{Al}_{2} \mathrm{O}_{3}$ and $\mathrm{SiO}_{2}$ in $\mathrm{CM}$ account for 3.35 and 29.98wt\%, respectively. In addition, $\mathrm{Al}_{2} \mathrm{O}_{3}$ and $\mathrm{SiO}_{2}$ serve to generate products with cementing properties (Pokharel and Fall, 2013), resulting in the potential coagulation property of CM.

Table 1 Particle size distributions of PG and CM

\begin{tabular}{ccccccc}
\hline The particle size $(\mathbf{m m})$ & $\mathbf{2 . 0 0} \mathbf{0 . 5 0}$ & $\mathbf{0 . 5 0} \mathbf{0 . 2 5}$ & $\mathbf{0 . 2 5} \mathbf{0 . 0 7 5}$ & $\mathbf{0 . 0 7 5} \mathbf{0 . 0 5}$ & $\mathbf{0 . 0 5} \mathbf{0 . 0 0 5}$ & $<\mathbf{0 . 0 0 5}$ \\
\hline PG & $0.50 w t \%$ & $0.50 w t \%$ & $22.00 w t \%$ & $32.00 w t \%$ & $34.50 w t \%$ & $10.50 w t \%$ \\
CM & - & $0.20 w t \%$ & $6.90 w t \%$ & $6.90 w t \%$ & $84.30 w t \%$ & $1.70 w t \%$ \\
\hline
\end{tabular}

Table 2 Main chemical compositions of PG and CM

\begin{tabular}{cccccccccc}
\hline & $\mathrm{SiO}_{2}$ & $\mathrm{CaO}$ & $\mathrm{MgO}$ & $\mathrm{P}_{2} \mathrm{O}_{5}$ & $\mathrm{Al}_{2} \mathrm{O}_{3}$ & $\mathrm{CaF}_{2}$ & $\mathrm{Fe}_{2} \mathrm{O}_{3}$ & $\mathbf{S O}_{4}{ }^{2-}$ & others \\
\hline $\mathrm{PG}$ & $3.20 \%$ & $31.45 \%$ & $1.16 \%$ & $1.12 \%$ & $0.19 \%$ & $20.16 \%$ & $0.03 \%$ & $41.02 \%$ & $1.65 \%$ \\
$\mathrm{CM}$ & $29.98 \%$ & $37.21 \%$ & $2.14 \%$ & $2.61 \%$ & $3.35 \%$ & $19.08 \%$ & $1.02 \%$ & $2.93 \%$ & $1.68 \%$ \\
\hline
\end{tabular}

\subsection{Mechanical test}

The backfill slurry is prepared by mixing PG, CM and water with varied proportions and slurry concentrations (the total ratio of $P G$ and $C M$ ). The slurry was poured into a curing cube with the side length of $70.7 \mathrm{~mm}$ 
(Figure 1) when the slurry was mixed in homogeneous state. When the specimens become self-standing (as shown in Figure 1), they can be removed out of the curing cube and then transferred to an environmental chamber which can control the curing temperature $\left(20^{\circ} \mathrm{C}\right)$ and relative humidity ( $\left.\mathrm{RH} 90 \%\right)$. As the uniaxial compressive strength (UCS) is a very important parameter when judging the mechanical stability of CPB (Fall et al., 2008), uniaxial compressive tests were carried out by the CTS-500 machine for the different cemented PG backfill specimens at different curing times.
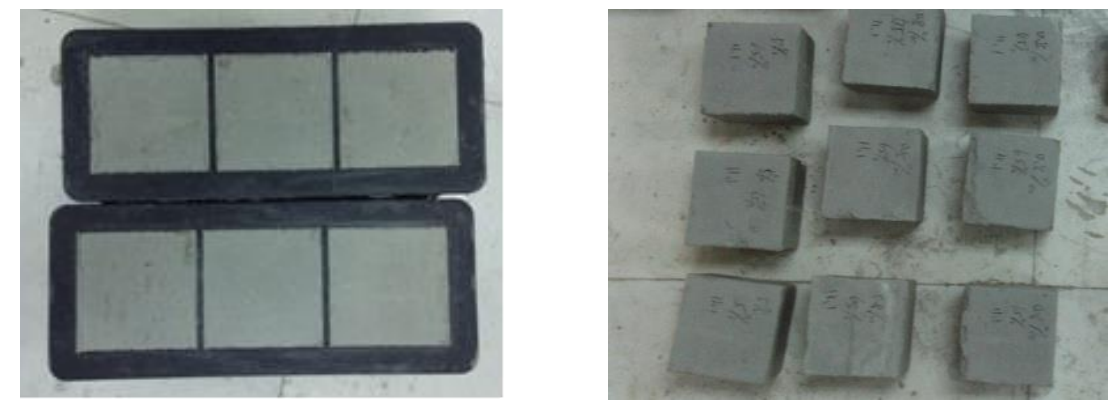

Figure 1 Cemented PG backfill specimens in curing cube and self-standing specimens

\section{$3 \quad$ Pipe test loop system}

The pipe test loop system was carried out in a backfill slurry prepare station. As shown in Figure 2, the pipe test loop system used stainless pipes with an inner diameter of $200 \mathrm{~mm}$ to simulate the industrial slurry transportation. The total length of loop pipeline was $141.5 \mathrm{~m}$, including that of the straight pipes, right-angle elbow and " $w$ " pipe. The backfill slurry was prepared in a slurry tank with a capacity of $15 \mathrm{~m}^{3}$. The pipe test loop system can obtain varied flow rates under different pump pressures offered by a centrifugal pump. Since the aim of pipe test loop was to measure the pressure drop of slurry flowing through pipes, the system should be equipped with precise measuring system. As shown in Figure 2, pressure transducer was employed to measure the total pressure drop of slurry flowing through the inlet and outlet of loop pipe. 1\# differential transducer can observe the differential pressure between two pressure tapings (No. 3 and 5) equipped on the straight pipe, while $2 \#$ differential pressure transducer was set to obtain the pressure drop of slurry flowing through the " $w$ " shape pipe through pressure tapings 6 and 8 . The distance between pressure tapings 3 and 5 is $15 \mathrm{~m}$, while the length of straight pipe between pressure tapings 6 and 8 is also $15 \mathrm{~m}$. In addition, an electromagnetic flow meter can be used to obtain the flowrate of slurry in the system. To ensure the accuracy of the results, a data acquisition system controlled by personal computer was also applied to automatically collect the data from electromagnetic flow meter, pressure transducers and differential pressure transducers.

Prior to the test, clean water usually circulated in the system for a certain period to ensure no mechanical problems occur. Then the water was completely drained out. During the test, the water content kept constant at $6 \mathrm{~m}^{3}$, and the slurry concentration was increased by adding the filling materials with the weight ratio of CM to PG 1:5. A density pot with fixed volume can be used to check if the mixing slurry has reached the target concentration. When the slurry flowed uniformly, the measuring equipment started to record data. At the end of the test, the slurry in the system would be drained to the filling pipe and recycled. Then the system was run with water again to clean the pipes and slurry tank. 


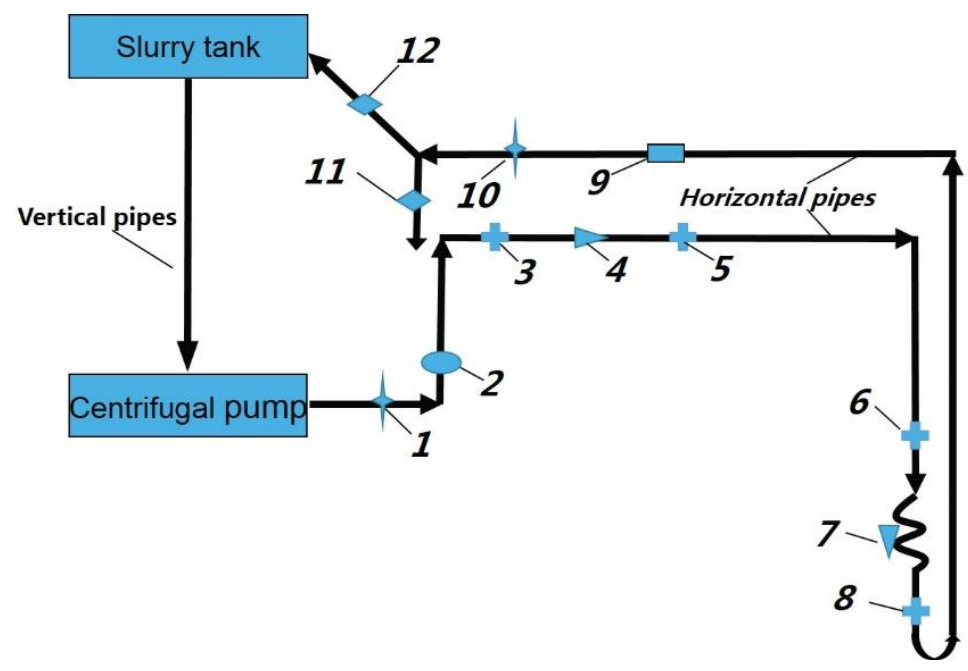

1-1\# Pressure transducer $\quad$ 2- The outlet for obtaining slurry sample 3,5,6,8-Pressure taping 4-1\# Differential pressure transducer 7-2\# Differential pressure transducer 9-Electromagnetic flow meter 10-2\# Pressure transducer 11-Drainage valve 12-Test valve

Figure 2 Schematic layout of pipe test loop system

\section{$4 \quad$ Results and discussion}

\subsection{Uniaxial compressive strength}

As listed in Table 3, the UCS of cemented PG backfill specimens is influenced by the slurry concentration, the mixing proportion of $C M$ to $P G$, and curing time. Assume the UCS values of specimens at curing time of 7, 14 and 28 days are $\delta_{7}, \delta_{14}$ and $\delta_{28}$, respectively. The relative change of UCS of specimens in early age ( $\left.\sigma_{\text {early }}\right)$ and late age $\left(\sigma_{\text {late }}\right)$ can be calculated by the following equations:

$$
\begin{gathered}
\sigma_{\text {early }}=\frac{\delta_{14}-\delta_{7}}{\delta_{7}} \\
\sigma_{\text {late }}=\frac{\delta_{28}-\delta_{14}}{\delta_{14}}
\end{gathered}
$$

Figure 3 shows the effect of CM to PG ratio on the UCS of specimens (slurry concentration is controlled at $70 w t \%$ ), while the relationship of slurry concentration to the UCS of specimens is illustrated in Figure 4 (with a mixing ratio of CM to PG being 1:4). It can be observed by Figures 3 and 4 that:

(1) With the increase of curing time, the UCS values of cemented PG backfill specimens increase when the mixing ratio of $C M$ to $P G$ is identical with the slurry concentration.

(2) When the slurry concentration is equal to $70 \mathrm{wt} \%$, UCS increases with the amount of CM added, indicating that $\mathrm{CM}$ is certainly capable of increasing the UCS value of cemented PG backfill specimens. In addition, the diversity of UCS value of cemented PG backfill specimens with different amount of $\mathrm{CM}$ added is more obvious at 28 days of curing.

(3) When the ratio of the added CM to PG is $1: 4$, it is obvious that the cemented PG backfill specimen with a higher slurry concentration shows a higher UCS value. In addition, as listed in Table 3 , the value of $\sigma_{\text {early }}$ in most cases exceed the $\sigma_{\text {late }}$, indicating a more obvious hydrated reaction at the early age. 
Table 3 The UCS values of different specimens

\begin{tabular}{|c|c|c|c|c|c|c|}
\hline \multirow{2}{*}{ Slurry Concentration } & \multirow{2}{*}{$m(C M): m(P G)$} & \multicolumn{3}{|c|}{ UCS(MPa) } & \multirow{2}{*}{$\sigma$ early } & \multirow{2}{*}{$\sigma$ late } \\
\hline & & 7 day & 14 day & 28 day & & \\
\hline \multirow{3}{*}{$68 w t \%$} & $1: 2$ & 0.306 & 1.619 & 3.422 & 4.29 & 1.11 \\
\hline & $1: 4$ & 0.204 & 0.766 & 2.354 & 2.75 & 2.07 \\
\hline & $1: 8$ & 0.122 & 0.184 & 0.408 & 0.51 & 1.22 \\
\hline \multirow{4}{*}{$70 w t \%$} & $1: 2$ & 0.966 & 2.857 & 6.817 & 1.96 & 1.39 \\
\hline & $1: 4$ & 0.408 & 1.388 & 3.320 & 2.40 & 1.39 \\
\hline & 1:6 & 0.157 & 0.333 & 0.830 & 1.12 & 1.49 \\
\hline & $1: 8$ & 0.095 & 0.211 & 0.259 & 1.22 & 0.23 \\
\hline \multirow{3}{*}{$72 w t \%$} & $1: 2$ & 0.524 & 2.687 & 5.959 & 4.13 & 1.22 \\
\hline & $1: 4$ & 0.476 & 1.435 & 4.503 & 2.01 & 2.14 \\
\hline & 1:6 & 0.136 & 0.340 & 0.898 & 1.50 & 1.64 \\
\hline
\end{tabular}

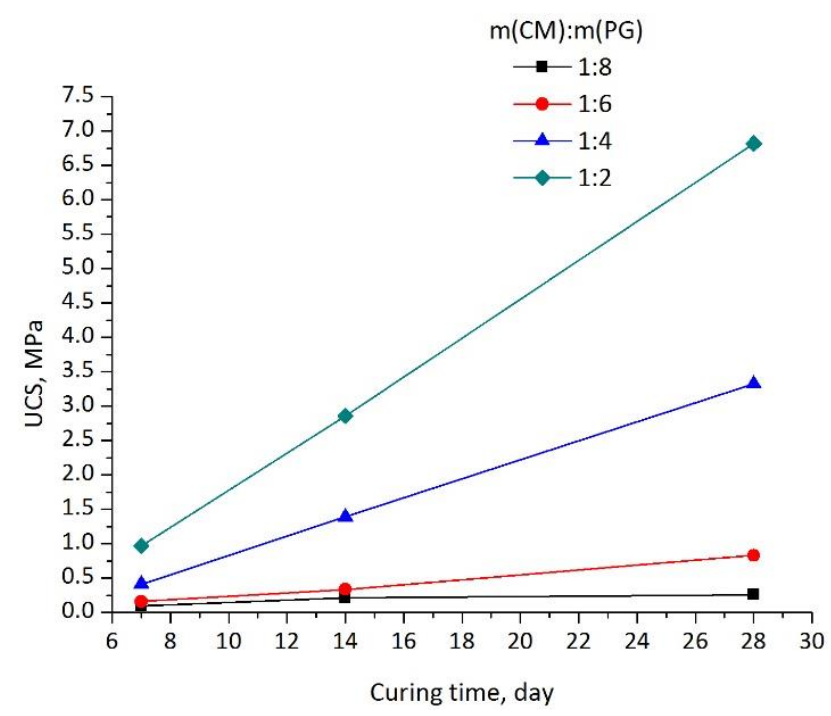

Figure 3 UCS of different specimens with different mixing ratios (slurry concentration controlled at $70 \mathrm{wt} \%$ )

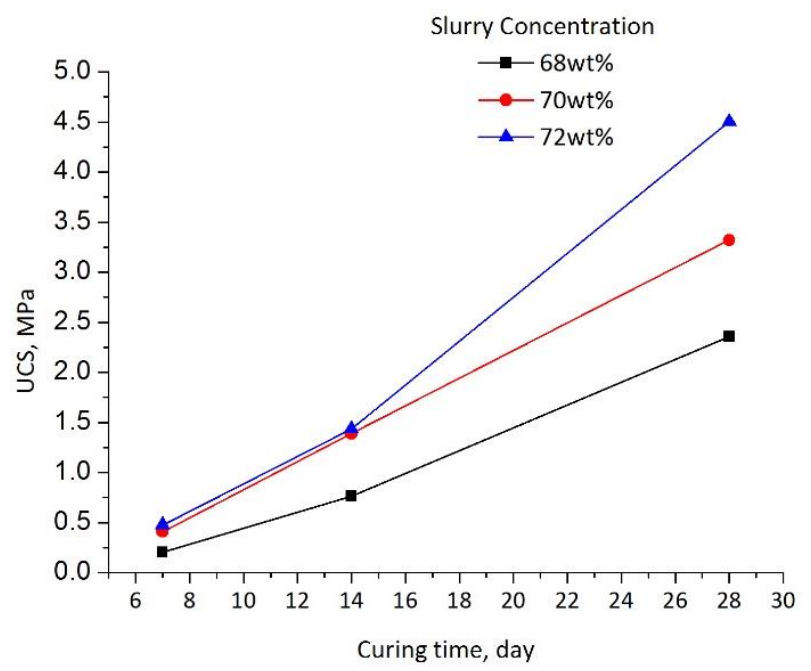

Figure 4 Effects of slurry concentration on UCS of cemented PG backfill specimens (m(CM):m(PG)=1:4) 


\subsection{Transportability and pressure drop calculation formulas}

The loop test system has examined a number of cemented PG backfill slurry with different slurry concentrations and flow rates. As illustrated in Figure 2, the partial pressure drop of backfill slurry flowing through the straight pipe with a distance of $15 \mathrm{~m}$ was recorded by $1 \#$ differential pressure transducer. Following that, the pressure drop of the slurry flowing through per unit length of pipe $\left(j_{m}\right)$ can be obtained by the following equation:

$$
j_{m}=\frac{\Delta p}{L}
$$

Where $\Delta p$ is the reading of $1 \#$ differential pressure transducer, while $L$ is the distance between pressure tapings 3 and 5 .

The PG backfill slurry with concentrations ranging from 63 to $67 \mathrm{wt} \%$ can be treated as paste slurry (Wang et al., 2011), with the slump ranging from 20 to $25 \mathrm{~cm}$ and bleeding rate from 1.5 to $5 \%$. Hence, the PG backfill slurry with concentrations varying from 60 to $63 \mathrm{wt} \%$ can be treated as paste-like backfill slurry. The flow model of paste slurry can be treated as Bingham plastic flow model, where the shear stress is in linear relationship with the shear rate. In addition, the relationship among shear stress, flowing velocity and $j_{m}$ can be described as follows by using Buckingham equation:

$$
\begin{gathered}
\tau_{w}=\frac{4}{3} \tau_{0}+\eta \times\left(\frac{8 v}{D}\right) \\
\tau_{w}=\frac{D}{4} \times \frac{\Delta p}{L}
\end{gathered}
$$

Where $\tau_{w}$ is the shear stress near the inner wall of the pipe, $v$ is the mean velocity of the flowing slurry, $\tau_{0}$ is the yield stress, $\eta$ is the plastic viscosity, and $D$ is the inner diameter of the pipe.

The value of yield stress and plastic viscosity can be obtained by the linear regression function, with the result listed in Table 4.

Table 4 Viscosity and yield stress of the CPPB slurry with different slurry concentrations

\begin{tabular}{cccc}
\hline Slurry Concentration & $\begin{array}{c}\text { Plastic viscosity } \boldsymbol{\eta} \\
(\mathbf{P a} \cdot \mathbf{s})\end{array}$ & $\begin{array}{c}\text { Yield stress } \boldsymbol{\tau}_{0} \\
(\mathbf{P a})\end{array}$ & $\begin{array}{c}\text { Correlation coefficient } \\
\mathbf{R}\end{array}$ \\
\hline $60 \mathrm{wt} \%$ & 0.1840 & 1.97 & 0.956 \\
$61 \mathrm{wt} \%$ & 0.2287 & 2.03 & 0.982 \\
$63 \mathrm{wt} \%$ & 0.2737 & 2.20 & 0.964 \\
$65 \mathrm{wt} \%$ & 0.6776 & 9.97 & 0.980 \\
\hline
\end{tabular}

Using Equations (3), (4), and (5), $j_{m}$ can be described as follows:

$$
j_{m}=\frac{16}{3 D} \times \tau_{0}+\eta \times \frac{32 v}{D^{2}}
$$

As shown in Table 4, both plastic viscosity $\eta$ and yield stress $\tau_{0}$ vary with the corresponding slurry concentration. Their relationships can be expressed by a new equation which can be more conveniently applied to industrial operations. With the help of the numerical fitting function of OriginPro, as plotted in Figures 5 and 6 , both $\eta$ and $\tau_{0}$ correlate well with the slurry concentration in power exponent relationships.

$$
\begin{array}{cc}
\tau_{0}=2 \times 10^{-8} \times \exp (30.539 C) & 60 w t \% \leq C \leq 65 w t \% \\
\eta=7 \times 10^{-8} \times \exp (24.481 C) & 60 w t \% \leq C \leq 65 w t \%
\end{array}
$$

Using Equations (7) and (8), when CM and PG are mixed in the mass ratio of 1:5, the pressure drop of CPPB slurry flowing through horizontal straight pipes can be calculated through the following equation: 


$$
\begin{aligned}
j_{m}=\frac{16}{3 D}\left(2 \times 10^{-8} \times \exp (30.539 C)\right)+\frac{32 v}{D^{2}}\left(7 \times 10^{-8} \times \exp (24.481 C)\right) \\
60 w t \% \leq C \leq 65 w t \%
\end{aligned}
$$

When $\mathrm{CM}$ and PG are mixed in the mass ratio of 1:4, the pressure drop of CPPB slurry can also be calculated in the same way:

$$
\begin{array}{r}
j_{m}=\frac{16}{3 D}\left(4.7 \times 10^{-17} \times \exp (60.781 C)\right)+\frac{32 v}{D^{2}}\left(7.2 \times 10^{-14} \times \exp (44.366 C)\right) \\
64 w t \% \leq C \leq 68 w t \%
\end{array}
$$

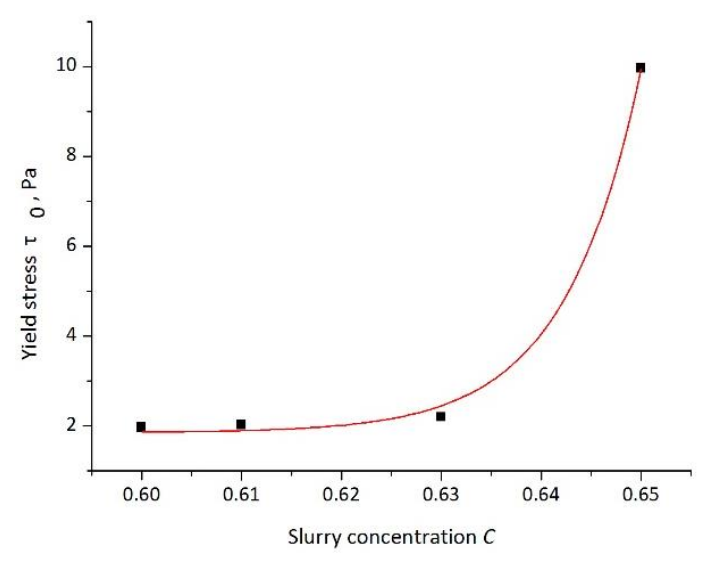

Figure 5 Relationship between $\tau_{0}$ and $C$

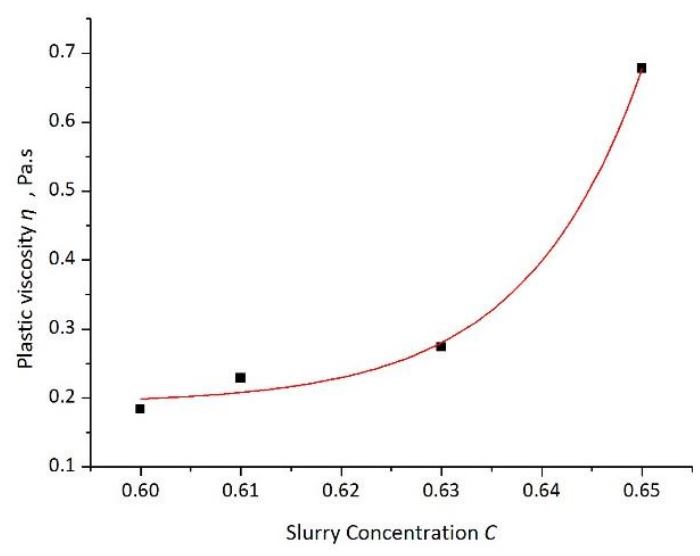

Figure 6 Relationship between $\eta$ and $C$

In order to validate Equation (9), a field test has been conducted in Guizhou Kailin Mining Corporation, Guiyang, China. The CPPB slurry was first prepared at ground station (the ratio of CM to PG being 1:5), and then transported to underground empty stopes by plunger pump. During the test, the maximum slurry flow rate offered by the plunger pump was $108 \mathrm{~m}^{3}$ per hour. The filling pipes through the inclined shaft and crosscut (main pipes) had an inner diameter of $125 \mathrm{~mm}$, while that of the other part (branch pipes) of the filling pipes was $100 \mathrm{~mm}$. Similar to the loop test, an electromagnetic flow meter was installed to measure the slurry flow rate and four pressure gauges were equipped to obtain the pressure of different places in the filling pipe system. Detailed information regarding the four pressure gauges are provided in Table 5.

Table 5 Details of pressure gauges

\begin{tabular}{lrc}
\hline Gauge number & Location & Measuring range \\
\hline 1\# pressure gauge & Near the slurry prepare station & $0 \sim 10 \mathrm{MPa}$ \\
2\# pressure gauge & The highest place in the filling pipeline system & $0 \sim 10 \mathrm{MPa}$ \\
3\# pressure gauge & The connection of main pipes and branch pipes & $0 \sim 6 \mathrm{MPa}$ \\
4\# pressure gauge & Near the outlet of filling pipes & $0 \sim 1 \mathrm{MPa}$ \\
\hline
\end{tabular}


The pressure at the $4 \#$ pressure gauge point was low enough to be regarded as zero. Since the distance between each pressure gauge can be measured in sites, the pressure values at the other three gauge points can be calculated by Equation (9). The calculation and the observation results by pressure gauges are both shown in Table 6. It can be found that the relative error between the calculated and observed results is less than $10 \%$, which indicates that the fitting calculation formulas for the pressure drop of PG paste slurry is reliable and hence, can be used to predict the pressure drops in backfilling technology.

Table 6 Comparison of calculated and observed pressure values at the points of pressure gauges

\begin{tabular}{lccccc}
\hline & Calculated value (MPa) & Observed value (MPa) & $\begin{array}{c}\text { Relative error } \\
(\%)\end{array}$ & $\begin{array}{c}\text { Flow rate } \\
\left(\mathbf{m}^{\mathbf{3}} / \mathbf{h}\right)\end{array}$ & slurry concentration \\
\hline \multirow{2}{*}{ Gauge 1 } & 5.92 & 6.00 & -1.33 & 70 & \\
& 5.03 & 5.00 & 0.60 & 60 & \\
\multirow{2}{*}{ Gauge 2 } & 5.67 & 5.80 & -2.24 & 70 & $65 \mathrm{wt} \%$ \\
& 4.79 & 4.50 & 6.44 & 60 & \\
Gauge 3 & 4.14 & 4.80 & -13.75 & 70 & \\
& 3.61 & 3.80 & -5.00 & 60 & \\
\hline
\end{tabular}

\section{$5 \quad$ Conclusions}

The cemented PG backfill specimen, which is fabricated by mixing CM, PG and water in certain proportions, has a significant strength. The uniaxial compressive strength (UCS) is influenced by the ratios of CM to PG, slurry concentration and curing time.

Both CM contents and slurry concentrations can increase the UCS of cemented PG backfill specimens. The long-term UCS of specimens with different amount of CM added is more remarkable than their short-term UCS.

The fitting calculation formulas for the pressure drop of CPPB slurry with two different ratios of cementitious materials to phosphogypsum (1:4 and 1:5, respectively) flowing through per unit length of horizontal straight pipe $\left(j_{m}\right)$ are obtained by treating the flowing of CPPB slurry as a Bingham plastic flow model. A field test was carried out that proved the reliability of conducted fitting calculation formula.

\section{Acknowledgements}

The authors would like to acknowledge the financial supports from the National Natural Science Foundation of China (Grant No.51474250) and the National Key R \& D Program of China (Grant No. 2016YFC0600706).

\section{References}

Akın, A.I. and Sert, Y. 2004, 'Utilization of weathered phosphogypsum as set retarder in portland cement', Cement and Concrete Research, vol. 34, issue 4, pp. 677-680.

Amaratunga, L.M. and Yaschyshyn, D.N. 1997, 'Development of a high modulus paste fill using fine gold mill tailings', Geotechnical \& Geological Engineering, vol. 15, issue 3, pp. 205-219.

Carbonell, B.A., DeLaune, R.D. and Jugsujinda, A. 2002, 'Phosphogypsum chemistry under highly anoxic conditions', Waste Management, vol. 22, issue 6, pp. 657-665.

Chen, J.S., Zhao, B., Wang, X.M., Zhang, Q.L. and Wang, L. 2010, 'Cemented backfilling performance of yellow phosphorus slag', International Journal of Minerals, Metallurgy, and Materials, vol. 17, issue 1, pp. 121-126.

Değirmenci, N. 2008, 'Utilization of phosphogypsum as raw and calcined material in manufacturing of building products', Construction and Building Materials, vol. 22, issue 8, pp. 1857-1862 
Fall, M., Benzaazoua, M. and Ouellet, S. 2004, 'Effect of tailings properties on paste backfill performance'. Proceedings of 8th International Symposia on Mining with Backfill, Beijing,China, pp. 193-202.

Fall, M., Benzaazoua, M. and Saa, E.G. 2008, 'Mix proportioning of underground cemented tailings backfill', Tunnelling and Underground Space Technology, vol. 23, issue 1, pp. 80-90.

Fall, M., Célestin, J.C., Pokharel, M. and Touré, M. 2010, 'A contribution to understanding the effects of curing temperature on the mechanical properties of mine cemented tailings backfill', Engineering Geology, vol. 114, issue 3-4, pp. 397-413.

Hewitt, D., Allard, S. and Radziszewski, P. 2009, 'Pipe lining abrasion testing for paste backfill operations', Minerals Engineering, vol. 22, issue 12, pp. 1088-1090.

Jiang, H., Fall, M. and Cui, L. 2016, 'Yield stress of cemented paste backfill in sub-zero environments: experimental results', Minerals Engineering, vol. 92, pp. 141-150.

Kesimal, A., Yilmaz, E., Ercikdi, B., Alp, I. and Deveci, H. 2005, 'Effect of properties of tailings and binder on the short-and long-term strength and stability of cemented paste backfill', Materials Letters, vol. 59, issue 28, pp. 3703-3709.

Lebedeva, O.E., Dubovichenko, A.E., Kotsubinskaya, O.I. and Sarmurzina, A.G. 2000, 'Preparation of porous glasses from phosphorus slag', Journal of Non-Crystalline Solids, vol. 277, issue 1, pp. 10-14.

Li, X., Zhou, Z., Zhao, G. and Liu, Z. 2008, 'Utilization of phosphogypsum for backfilling, way to relieve its environmental impact', Gospodarka Surowcami Mineralnymi, vol. 24, issue 4, pp. 225-231.

Mun, K.J., Hyoung, W.K., Lee, C.W., So, S.Y. and Soh, Y.S. 2007, 'Basic properties of non-sintering cement using phosphogypsum and waste lime as activator', Construction and Building Materials, vol. 21, issue 6, pp. 1342-1350.

Parreira, A.B., Kobayashi, A.R.K. and Silvestre, O.B. 2003, 'Influence of portland cement type on unconfined compressive strength and linear expansion of cement-stabilized phosphogypsum', American Society of Civil Engineers, vol. 129, issue 10, pp. 956-960.

Pokharel, M. and Fall, M. 2013, 'Combined influence of sulphate and temperature on the saturated hydraulic conductivity of hardened cemented paste backfill', Cement and Concrete Composites, vol. 38, pp. 21-28.

Tayibi, H., Choura, M., Lopez, F.A., Alguacil, F.J. and Lopez-Delgado, A. 2009, 'Environmental impact and management of phosphogypsum', Journal of environmental management, vol. 90, issue 8, pp. 2377-2386.

Wang, H., Wang, Y., Wu, A., Zhai, Y. and Jiao, H. 2011, 'Research of paste new definition from the viewpoint of saturation ratio and bleeding rate', Journal of Wuhan University of Technology, vol. 33, issue 6, pp. 85-89.

Wu, D., Yang, B. and Liu, Y. 2015, 'Pressure drop in loop pipe flow of fresh cemented coal gangue-fly ash slurry: Experiment and simulation', Advanced Powder Technology, vol. 26, issue 3, pp. 920-927.

Wu, D., Yang, B. and Liu, Y. 2015, 'Transportability and pressure drop of fresh cemented coal gangue-fly ash backfill (CGFB) slurry in pipe loop', Powder Technology, vol. 284, pp. 218-224.

Yang, J., Liu, W., Zhang, L. and Xiao, B. 2009, 'Preparation of load-bearing building materials from autoclaved phosphogypsum', Construction and Building Materials, vol. 23, issue 2, pp. 687-693.

Yilmaz, E. 2010, 'Investigating the hydrogeotechnical and microstructural properties of cemented paste backfill using the CUAPS apparatus', Ph.D. Thesis. Universitédu Québec en Abitibi-Témiscamingue (UQAT).

Zhou, J., Gao, H., Shu, Z., Wang, Y. and Yan, C. 2012, 'Utilization of waste phosphogypsum to prepare non-fired bricks by a novel Hydration-Recrystallization process', Construction and Building Materials, vol.34, pp. 114-119. 